\title{
Systemic absorption of oral vancomycin in a peripheral blood stem cell transplant patient with severe graft-versus-host disease of the gastrointestinal tract
}

J.M. Pogue, D.D. DePestel, D.R. Kaul,Y. Khaled, D.G. Frame. Systemic absorption of oral vancomycin in a peripheral blood stem cell transplant patient with severe graft-versus-host disease of the gastrointestinal tract.

Transpl Infect Dis 2009: 11: 467-470. All rights reserved

Abstract: Oral vancomycin is often considered the drug of choice for severe Clostridium difficile-associated disease due to both its efficacy and pharmacokinetics. The potential for absorption is not well described in patients with impaired gastrointestinal (GI) mucosa. We describe a case of significant and potentially toxic absorption of oral vancomycin in a peripheral blood stem cell transplant patient with grade IV graft-versus-host disease (GVHD) of the GI tract. In patients with GI GVHD clinicians need to be aware of the potential for oral absorption and, in select cases, monitoring of levels may be appropriate.

\begin{abstract}
J.M. Pogue', D.D. DePestel ${ }^{2,3}$, D.R. Kaul ${ }^{4}$, Y. Khaled ${ }^{5}$, D.G. Frame ${ }^{2,3}$

${ }^{1}$ Department of Pharmacy Services, Sinai Grace Hospital, Detroit Medical Center, Detroit, Michigan, USA, ${ }^{2}$ Department of Clinical, Social, and Administrative Sciences, University of Michigan College of Pharmacy, Ann Arbor, Michigan, USA, ${ }^{3}$ Department of Pharmacy Services, University of Michigan Health System, Ann Arbor, Michigan, USA, ${ }^{4}$ Department of Internal Medicine, Division of Infectious Diseases, University of Michigan Medical School, Ann Arbor, Michigan, USA, and ${ }^{5}$ Blood and Marrow Transplantation Program, University of Michigan Health System, Ann Arbor, Michigan, USA
\end{abstract}

Key words: Clostridium difficile; CDAD; vancomycin; GVHD; graft-versus-host disease; peripheral blood stem cell transplant

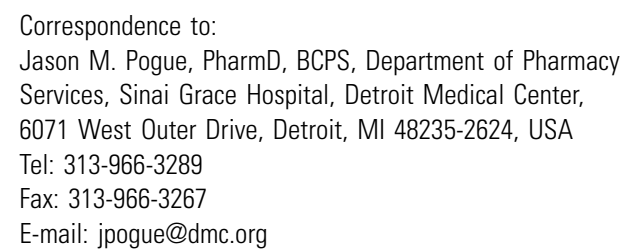

Received 15 January 2009, revised 26 March, 6 April 2009, accepted for publication 13 April 2009

DOl: 10.1111/j.1399-3062.2009.00426.x Transpl Infect Dis 2009: 11: 467-470
Oral vancomycin is a routinely used agent for the treatment of Clostridium difficile-associated diarrhea (CDAD). National experts recommend oral vancomycin for severe CDAD based on selected literature that supports an increase in efficacy over metronidazole (1) and the fact that the drug reaches concentrations $\geq 1000$ times the minimum inhibitory concentration of the organism at the site of action without significant systemic absorption (2). These recommendations and the emergence of the more virulent, NAP-1 strain have led to a more widespread use of oral vancomycin in patient populations where both efficacy and the potential for systemic absorption have not been well stud-
ied.We report a case of significant and potentially toxic absorption of oral vancomycin in a peripheral blood stem cell transplant (PBSCT) recipient with severe gastrointestinal (GI) graft-versus-host disease (GVHD).

\section{Case report}

A 62-year-old male with myelodysplastic syndrome underwent a 10/10 HLA-matched unrelated donor PBSCT that was complicated by grade I acute GI GVHD, cytomegalovi- 
rus reactivation, and human herpesvirus- 6 encephalopathy. On day +200 after transplant, he was readmitted with 4-6 episodes of diarrhea daily (average stool output 1.5$2 \mathrm{~L} /$ day) and he was found to have $C$. difficile, as well as grade IV GI GVHD. The computed tomography findings demonstrated congestion in the mucosa throughout the colon and the histopathologic findings were most consistent with severe (grade IV) GVHD.

However, the patient had several risk factors for $C$. diffcile, including recent antibiotic use, acid suppression therapy, recent prolonged hospitalization, advanced age, and severe underlying illness due to GVHD and immunosuppression. The white blood cell count was within the normal range and pseudomembranes were not present on endoscopy; nevertheless, the diagnosis of $C$. difficile colitis was made on the basis of clinical findings in conjunction with a positive stool toxin assay (ProSpec $\mathrm{T}^{\circledR} \mathrm{C}$. difficile toxin Toxin A/B Microplate Assay; Remel Inc., Lenexa, Kansas, USA). Oral vancomycin $250 \mathrm{mg}$ solution was initiated every $6 \mathrm{~h}$ along with rifaximin $200 \mathrm{mg} 3$ times a day for presumed severe CDAD while methylprednisolone $2 \mathrm{mg} / \mathrm{kg} /$ day intravenously was started for GVHD. Throughout the patient's course he also received 5 days of mycophenolate, 17 days of cyclosporine, 13 days of oral budesonide, and 4 days of sirolimus. The patient did not receive intravenous vancomycin during his hospitalization.

The patient's serum creatinine began to increase on hospital day 19 and, as a result, a vancomycin level was ordered and found to be $26.4 \mathrm{mg} / \mathrm{L}$. The vancomycin was held for the next 4 days, while rifaximin was continued, with a subsequent return to the patient's baseline renal function (serum creatinine $1.5 \mathrm{mg} / \mathrm{dL}$ ) and a corresponding decrease in vancomycin concentration $(5.9 \mathrm{mg} / \mathrm{L})$. Table 1 displays his vancomycin doses and levels, as well as his serum creatinine levels.

On hospital day 25 , oral vancomycin was restarted at a reduced dose of $125 \mathrm{mg}$ every $6 \mathrm{~h}$. On day 28 of hospitalization, the vancomycin dose was again increased to $250 \mathrm{mg}$ every $6 \mathrm{~h}$ because the patient was still having severe diarrhea. Six days after the dosage increase, a second rise in serum creatinine was observed with a corresponding vancomycin level of $13.3 \mathrm{mg} / \mathrm{L}$. The patient went on to develop bacteremia with vancomycin-resistant Enterococcus faecium and Candida glabrata, and he died on hospital day 35 .

\section{Discussion}

Case reports (Table 2) describe the significant accumulation of oral vancomycin in selected patients with renal insufficiency (3-7), and a more recent case report (8) showed
Vancomycin concentrations in serum

\begin{tabular}{|c|c|c|c|c|}
\hline $\begin{array}{l}\text { Hospital } \\
\text { day }\end{array}$ & $\begin{array}{l}\text { Oral } \\
\text { vancomycin } \\
\text { dose } \\
\text { (mg p.o.q6h) }\end{array}$ & $\begin{array}{l}\text { Level } \\
(\mathrm{mg} / \mathrm{L})\end{array}$ & $\begin{array}{l}\text { Serum } \\
\text { creatinine }\end{array}$ & $\begin{array}{l}\text { Clostridium } \\
\text { difficile toxins }\end{array}$ \\
\hline 1 & N/A & N/A & 1.5 & + \\
\hline $4-17$ & 250 & N/A & $1.0-1.5$ & $\mathrm{~N} / \mathrm{A}$ \\
\hline 18 & 250 & N/A & 1.3 & + \\
\hline 19 & 250 & N/A & 1.7 & $\mathrm{~N} / \mathrm{A}$ \\
\hline 20 & Held & $\begin{array}{l}C(1)=26.4 \\
C(t r)=24\end{array}$ & 2.1 & N/A \\
\hline 21 & Held & $22.1,22.6$ & 2.0 & $\mathrm{~N} / \mathrm{A}$ \\
\hline 22 & Held & 15.1 & 1.8 & N/A \\
\hline 23 & Held & $\mathrm{N} / \mathrm{A}$ & 1.6 & $\mathrm{~N} / \mathrm{A}$ \\
\hline 24 & Held & 8.6 & 1.5 & $\mathrm{~N} / \mathrm{A}$ \\
\hline 25 & $125^{1}$ & 5.9 & 1.4 & N/A \\
\hline 26 & $125^{1}$ & $\mathrm{~N} / \mathrm{A}$ & 1.3 & $\mathrm{~N} / \mathrm{A}$ \\
\hline 27 & $125^{1}$ & 5.0 & 1.4 & $\mathrm{~N} / \mathrm{A}$ \\
\hline 28 & $250^{1}$ & 4.4 & 1.4 & $\mathrm{~N} / \mathrm{A}$ \\
\hline 29 & $250^{2}$ & N/A & 1.5 & $\mathrm{~N} / \mathrm{A}$ \\
\hline 30 & $250^{3}$ & 3.7 & 1.5 & $\mathrm{~N} / \mathrm{A}$ \\
\hline $31-33$ & 250 & $\mathrm{~N} / \mathrm{A}$ & $1.5-2.2$ & $\mathrm{~N} / \mathrm{A}$ \\
\hline 34 & Held & 13.3 & 2.6 & $\mathrm{~N} / \mathrm{A}$ \\
\hline 35 & Held & 16.3 & $\begin{array}{l}2.8- \\
\text { patient } \\
\text { died }\end{array}$ & $\mathrm{N} / \mathrm{A}$ \\
\hline \multicolumn{5}{|c|}{$\begin{array}{l}{ }^{1} \text { Patient received } 2 \text { doses of vancomycin. } \\
{ }^{2} \text { Patient received } 1 \text { dose of vancomycin. } \\
{ }^{3} \text { Patient received } 3 \text { doses of vancomycin. } \\
C(1) \text {, concentration at } 1 \text { h after oral dose; } C(\operatorname{tr}) \text {, trough concentration; } \\
\text { N/A, not available. }\end{array}$} \\
\hline
\end{tabular}

Table 1

significant systemic vancomycin levels in a patient with severe $C$. difficile disease with normal renal function. The package insert for Vancocin ${ }^{\circledR}$ pulvules (Eli Lilly, Indianapolis, Indiana, USA) states that 'significant absorption may infrequently occur in patients with $C$. difficile-induced pseudomembranous colitis, and, in the presence of renal impairment, the possibility of accumulation exists' (2). However, systemic absorption of oral vancomycin has not been reported to our knowledge in a patient with severe GI GVHD.

We present a case of significant oral vancomycin absorption in a PBSCT patient with severe GI GVHD. Based on the timing of the vancomycin levels and patient's underlying illness, it is difficult to ascertain whether high levels of vancomycin led to renal insufficiency, or if it was the impaired renal function that led to the accumulation of vancomycin. Regardless of the exact mechanism, this patient had both clinically relevant and potentially toxic vancomycin con- 


\begin{tabular}{|c|c|c|c|c|c|}
\hline $\begin{array}{l}\text { Number of } \\
\text { patients }\end{array}$ & $\begin{array}{l}\text { Age (years) } \\
\text { Sex }\end{array}$ & $\begin{array}{l}\text { Oral vancomycin } \\
\text { dose (mg p.o.q6h) }\end{array}$ & Serum creatinine & Level (mg/L) & References \\
\hline 1 & $62 \mathrm{M}$ & 500 & $H D$ & $11.3-20.3$ & (3) \\
\hline 1 & $32 \mathrm{M}$ & 250 & $\mathrm{HD}$ & 5.8 & $(4)$ \\
\hline 1 & $45 \mathrm{M}$ & 250 & $\mathrm{HD}$ & 2.6 & (4) \\
\hline 1 & $45 \mathrm{M}$ & 500 & $\mathrm{HD}$ & $11-13$ & $(4)$ \\
\hline 1 & $45 \mathrm{M}$ & 125 & $\mathrm{HD}$ & 3.4 & (4) \\
\hline 1 & $28 \mathrm{M}$ & 500 & $H D$ & $0.7-9.8$ & $(4)$ \\
\hline 10 & $14-81 \mathrm{M} / \mathrm{F}$ & 125 & $\begin{array}{l}\text { Ranged from normal } \\
\text { to severe impairment }\end{array}$ & $\begin{array}{l}\text { 4/11 patients with detectable } \\
\text { (1.0-3.1) levels }\end{array}$ & (5) \\
\hline 10 & N/A & 500 & N/A & $\begin{array}{l}1 \text { patient with level of } 3.9, \\
\text { all others } \leq 1\end{array}$ & (6) \\
\hline \multirow[t]{5}{*}{12} & $\mathrm{~N} / \mathrm{A}$ & 500 & Normal & 8 had undetectable levels & (7) \\
\hline & $54 \mathrm{~F}$ & 500 & Normal & 2.4 & $(7)$ \\
\hline & $89 \mathrm{M}$ & 500 & 2.3 & 1.2 & (7) \\
\hline & $71 \mathrm{M}$ & 500 & 1.2 & 1.3 & $(7)$ \\
\hline & $66 \mathrm{~F}$ & 500 & $H D$ & 5.1 & $(7)$ \\
\hline 1 & $77 \mathrm{~F}$ & $\begin{array}{l}125-500+ \\
\text { vancomycin enemas }\end{array}$ & 1.0 & $6.3-7.9$ & (8) \\
\hline
\end{tabular}

Table 2

centrations, despite never receiving intravenous vancomycin. These data are particularly interesting in the light of 2 recent reports showing patients having systemic hypersensitivity-type adverse drug reactions attributed to oral vancomycin therapy $(10,11)$.

The diagnosis of CDAD and response to treatment can be challenging in this patient population. GI GVHD is common and is graded based on daily stool volume with grade I disease defined as stool output $>500 \mathrm{~mL} /$ day, grade II as $>1000 \mathrm{~mL} /$ day, grade III as $>1500 \mathrm{~mL} /$ day, and grade IV as $>2000 \mathrm{~mL} /$ day (12). Symptoms of GVHD and CDAD both often include fever and leukocytosis. Because the symptoms are similar, it is often difficult to ascertain the severity of the CDAD infection versus the GVHD. Given these diagnostic limitations, empirical treatment for severe CDAD with oral vancomycin is not uncommon in the setting of GI GVHD. As demonstrated in this report, loss of GI integrity may lead to increased bioavailability, and therefore, the potential for significant accumulation of vancomycin, and possible adverse effects. The additive nephrotoxicity based on drug interactions with other medications often co-administered for transplant, such as calcineurin inhibitors, sirolimus, and foscarnet, among others, would be of additional concern. Our patient was on multiple concomitant nephrotoxins. While the concen- tration of these agents was not considered toxic (sirolimus levels were undetectable and cyclosporine levels remained $<100 \mathrm{ng} / \mathrm{mL}$ ), additive toxicity with vancomycin cannot be ruled out.

We are not able to ascertain the relative contribution of CDAD or GI GVHD to the absorption of vancomycin, but the fact that the systemic level was high after 19 days of treatment (a time course during which most patients with CDAD would have improved) suggests that GI GVHD contributed to systemic absorption. If, as our case report suggests, oral vancomycin, which is generally considered to be nonabsorbable, can be absorbed in instances of severe GVHD, with or without severe CDAD, as a result of impaired intestinal integrity, might other non-absorbable drugs also be absorbed? Two agents that are commonly used in this patient population include rifaximin and budesonide. A combination of oral vancomycin and rifaximin has also been used to treat recurrent or persistent CDAD (13). Absorption of rifaximin could potentially lead to metabolic drug interaction with drugs such as azole antifungals or calcineurin inhibitors; and increased levels of systemic steroids could increase the risk of infection. While this warrants further investigation, it is essential to be aware of the potential for absorption of these "non-absorbable' drugs in patients with GI GVHD. 
The third question raised is the seemingly dosedependent absorption that is noted in all cases where significant absorption has been seen (3-5). A dose of $125 \mathrm{mg}$ every $6 \mathrm{~h}$ has been found to be equivalent to $500 \mathrm{mg}$ every $6 \mathrm{~h}$ for the treatment of CDAD (9). This would imply no added benefit in utilizing the higher dose. The decision to use a $500 \mathrm{mg}$ dose over a $125 \mathrm{mg}$ dose in this patient population could increase the risk of accumulation and potential toxicity.

The very conditions for which oral vancomycin is indicated - that is, severe disease marked by severe inflammation, potential renal insufficiency, and high stool outputs - may, in fact, be the very situations where oral absorption might be an issue. In treating patients with GI GVHD, clinicians need to be aware of the potential for oral absorption and, in select cases, monitoring of levels may be appropriate.

\section{References}

1. Zar FA, Bakkanagari SR, Moorthi KM, Davis MB. A comparison of vancomycin and metronidazole for the treatment of Clostridium difficile-associated diarrhea, stratified by disease severity. Clin Infect Dis 2007; 45: 302-307.

2. Product information. Vancocin (vancomycin hydrochloride capsules, USP pulvules). Indianapolis, IN: Eli Lilly and Company, 2000.
3. Spitzer PG, Eliopoulos GM. Systemic absorption of enteral vancomycin in a patient with pseudomembranous colitis. Ann Intern Med 1984; 100 (4): 533-534.

4. Matzke GR, Halstenson CE, Olson PL, Collins AJ, Abraham PA. Systemic absorption of oral vancomycin in patients with renal insufficiency and antibiotic-associated colitis. Am J Kidney Dis 1987; 5: $422-425$.

5. Armstrong CJ,Wilson TS. Systemic absorption of vancomycin. J Clin Pathol 1995; 48: 689

6. Tedesco F, Markham R, Gurwith M, Christie D, Bartlett JG. Oral vancomycin for antibiotic-associated pseudomembranous colitis. Lancet 1978; 2: 226-228.

7. Dudley MN, Quintiliani R, Nightingale, Gontarz N. Absorption of vancomycin. Ann Intern Med 1984; 101: 144.

8. Aradhyula S, Manian FA, Hafidh SA, Bhutto SS, Alpert MA. Significant absorption of oral vancomycin in a patient with Clostridium difficile colitis and normal renal function. South Med J 2005; 99 (5): 518-520.

9. Fekely R, Silva J, Kauffman, Buggy B, Deery HG. Treatment of antibiotic-associated Clostridium difficile colitis with oral vancomycin: comparison of two dosage regimens. Am J Med 1989; 86 (1): $15-19$.

10. Osawa R, Kaka A. Maculopapular rash induced by oral vancomycin. Clin Infect Dis 2008; 47: 880-881.

11. Bailey P, Gray H. An elderly woman with "Red Man Syndrome" in association with oral vancomycin therapy: a case report. Cases J 2008; 1: 111 .

12. Leisenring WM, Martin PJ, Petersdorf EW, et al. An acute graftversus-host disease activity index to predict survival after hematopoietic cell transplantation with myeloablative conditioning regimens. Blood 2006; 108 (2): 749-755.

13. Kelly C, LaMont JT. Clostridium difficile - more difficult than ever. N Engl J Med 2008; 359: 1932-1940. 